\title{
Balanço socioambiental do município de Novo Brasil/GO no exercício de 2014
}

Andressa Rodrigues de Oliveira ${ }^{1}, \underline{\text { Karlla Elizabeth Barros Rabelo }}{ }^{1}$, Marcela Barbosa de $\underline{\text { Paula }}^{1}$, Graciele Araújo de Oliveira Caetano ${ }^{2 *}, \underline{\text { Denise Gomes Barros Cintra }}^{3}$, Bruno de Ávila Debom Rey ${ }^{3}$

${ }^{1}$ Discentes do curso de Ciências Contábeis da Faculdade de Jussara/GO andressarodriguesoliveira@hotmail.com, karllaelizabeth@hotmail.com, marcelaa.barbosa@hotmail.com

${ }^{2}$ Professora de Contabilidade Ambiental, Mestre em Produção Animal, Faculdade de Jussara/GO gracielecaetano@outlook.com

3Professores especialistas em Contabilidade, Faculdade de Jussara/GO denise@unifaj.edu.br, brunodebomrey@hotmail.com

*Autor para correspondência

RESUMO. A Contabilidade é uma ciência que tem por finalidade o estudo das variações qualitativas e quantitativas ocorridas no patrimônio das entidades organizações ou empresas. Unindo essa ciência ao meio ambiente, tem-se a Contabilidade ambiental, que tem como foco principal o desenvolvimento sustentável, visando a estabilidade entre as atividades econômicas e os danos causados ao meio ambiente, regulando assim o ativo e o passivo ambiental tanto nas pequenas quanto nas grandes empresas. Com o passar do tempo, a proteção ambiental ganhou prioridade no setor social e no setor empresarial, e a sociedade passou a exigir uma nova postura ética das entidades. As empresas passaram a prestar contas de suas ações com o intuito de melhorar sua imagem através do enfoque à questão ambiental junto a consumidores e acionistas, pois diante das constantes mudanças globais, houve a necessidade de observar com maior relevância o meio ambiente. $\mathrm{O}$ Balanço Social é um conjunto de informações que evidencia as atividades de uma entidade, seja ela pública ou privada, com a sociedade, com objetivo de divulgar sua gestão econômico-social, e sobre o seu relacionamento com a comunidade, proporcionando o resultado de sua responsabilidade social. A estabilidade que se busca atingir entre o crescimento econômico e o desenvolvimento sustentável é conseguida através desse instrumento, também denominado balanço socioambiental. Como já previsto, algumas entidades ainda não se conscientizaram sobre a importância da existência de um Balanço Socioambiental, minimizando assim os benefícios procedentes dessa produção. $O$ presente trabalho teve o objetivo de elaborar $o$ Balanço Socioambiental da Prefeitura de Novo Brasil- Goiás, para demonstrar os indicadores financeiros e indicadores sociais e ambientais do ano 2014, assim como o reflexo que essas informações exercem na sociedade.

Palavras Chave: responsabilidade social, contabilidade ambiental, balanço social.

\section{Social and Environmental Balance of Novo Brasil/GO in the year 2014}

\begin{abstract}
ABSTRAC. Accountancy is a science that has the purpose to study the qualitative and quantitative variations in the organizations or business entities. Joining this science and environment, there is the environmental resource accounting, which focuses primarily on sustainable development for the stability of economic activities and the damage caused to the environment, thus regulating the environmental assets and liabilities in small and in large companies. Over time, environmental protection has achieved priority in social sector and the business sector, and the society began to demand a new ethical posture. The companies have to account for their actions in order to improve its image by focusing the environmental issue with stakeholders and shareholders, because of constant global
\end{abstract}


change, it was necessary to notice with greater relevance to the environment. The Social Report is a set of information that shows the entity activities, whether public or private, to society, in order to promote its economic and social management, and its relationship with the community, providing as the result its social responsibility. This stability which seeks to achieve economic growth and sustainable development is a tool also called environmental balance. As predicted, some entities haven't become aware of the importance of the existence of a Social and Environmental Balance, thus minimizing the benefits coming from this production. This study aimed to elaborate the Environmental Review of the municipality Novo Brasil - Goiás, in order to demonstrate the financial, social and environmental indicators for the year 2014 as well as the consequences that this information have on the society.

Keywords: social responsibility, environmental, accountancy, social report

\section{Introdução}

O presente estudo apresenta como méritos a reflexão sobre desenvolvimento econômico, desenvolvimento social, preservação e conservação do meio ambiente e suas interseções, cuja sincronia perfeita e harmônica, irá originar um mundo melhor com inserção social, ecoeficiência, justiça socioambiental, principalmente a importância da contabilidade ambiental e o balanço social no desenvolvimento sustentável.

Desta forma contabilidade é uma ciência que tem por desígnio o estudo das variações qualitativas e quantitativas ocorridos no patrimônio das entidades organizações ou empresas, ao unir essa ciência junto ao meio ambiente temos a contabilidade ambiental que tem como foco fundamental o desenvolvimento sustentável, visando à estabilidade entre as atividades econômicas e os prejuízos causados ao meio ambiente, ajustando assim o ativo e o passivo ambiental entre as pequenas e grandes empresas.

Na visão de Navarro \& Müller (2010), a contabilidade ambiental, além da colocação de orientar a empresa nos registros dos gastos e investimentos com o meio ambiente, tem como premissa levar o empresário a uma tomada de consciência na definição de que os recursos naturais não são abundantes, muito pelo contrário, alguns agravos causados à natureza são irreversíveis. Assim, o meio ambiente é um bem comum que deve ser cultivado e preservado para as gerações futuras.

A contabilidade ambiental possui benefícios tanto para as indústrias quanto para a sociedade, a contabilidade na gestão pública não irá resolver os problemas socioambientais, porem irá identificar mensurar e esclarecer os eventos e ajustes econômico-financeiros.
Em 1972 foi concretizada a primeira conferência, Conferência de Estocolmo na capital da Suécia, sendo a primeira atitude mundial a tentar preservar o meio ambiente. A partir dessa houve outras grandes conferências com o mesmo objetivo como exemplo, a ECO-92, RIO+10 e a $\mathrm{RIO}+20$.

A Contabilidade Ambiental pode ser mensurada e contabilizada, e já na década de 1930 foi criado um método para gerar um novo caráter ético no meio ambiente, nomeado por Balanço Social o principal instrumento de demonstrações contábeis na área pública e também um demonstrativo publicado pelas empresas unindo informações sociais.

O balanço Socioambiental surgiu para satisfazer as necessidades de informações e para aperfeiçoar a execução das atividades. Os gestores expressam suas informações por meio desses relatórios contábeis para a sociedade, pois ela tem o direito do conhecimento no que se passa em uma empresa, visto que empresa pública também deve prestar contas à sociedade. O Balanço Social é de bastante importância, pois nele existe uma melhor transparência das informações.

A contabilidade ambiental tem como principal foco o desenvolvimento sustentável e a conscientização, isso não surge apenas da sociedade, mas principalmente das empresas. Ela colabora no fornecimento de informações, ampara a responsabilidade social e ambiental, auxilia o processo de tomada de decisão das empresas, da cidadania e da sociedade, explanando que o desenvolvimento sustentável é uma rede em articulação constante.

Diante dos fatos o objetivo do presente trabalho será a elaboração do Balanço Socioambiental da Prefeitura de Novo Brasil Goiás, demostrando os benefícios proporcionados 
ao município, de forma qualitativa e quantitativa, e de forma aberta, com os valores financeiros e indicadores sociais e ambientais do ano de 2014.

\section{Revisão Bibliográfica}

\section{Contabilidade Ambiental}

A Contabilidade é uma ciência que tem por finalidade o estudo das variações qualitativas e quantitativas ocorridos no patrimônio das entidades, organização ou empresa. Foi criado pelo Frei Luca Paccioli, sendo o melhor sistema de informação de uma empresa que vem para promover na tomada de decisões.

O principal foco da contabilidade ambiental é o desenvolvimento sustentável e a conscientização. No mundo em constante mudança, surge o conceito de desenvolvimento sustentável e a preocupação com a qualidade ambiental. A contabilidade terá que lidar com uma nova realidade econômico-financeira das empresas, onde deve existir estabilização entre a atividade econômica e a exploração dos recursos naturais, através de certa mensuração dos impactos ambientais e dos seus reflexos nas empresas, pessoas e sociedade.

Podemos definir Contabilidade Ambiental como um conjunto de procedimentos visando identificar, mensurar e esclarecer os eventos e transações econômico-financeiros. Surgiu em 1960, se absorvendo tanto com os aspectos sociais e econômicos que envolvem as atividades das organizações, quanto com a produtividade necessária para o mercado consumidor, além de preocupar-se com os recursos humanos.

O combate a todas as formas de poluição é uma obrigação de toda a sociedade. Visto que várias ciências e áreas do conhecimento já estão se empenhando em contribuir para essa causa, de acordo com seu campo de atuação, impõe-se também a participação da ciência contábil (Ribeiro, 2006, p.44).

Segundo Ribeiro (1992, p.40), a contabilidade ambiental é importante para sancionar a preocupação tanto com os aspectos sociais e econômicos, quanto com a produtividade necessária para o mercado consumidor. Além de preocuparem-se com os recursos humanos utilizados na manutenção de atividades.

Há benefícios da contabilidade ambiental tanto para as indústrias quanto para a sociedade. Benefícios possíveis a Indústria: identifica e reduz os custos; controla o uso do fluxo de energia e dos materiais; da informações mais exatas. Benefícios possíveis a sociedade: permitir o uso mais competente de recursos naturais; reduz os custos relacionados a poluição da indústria; fornecer informação para a tomada de decisão; fornecer informação ambiental industrial da atuação.

A primeira atitude mundial a tentar preservar o meio ambiente foi realizada em 1972 na capital da Suécia e nomeada como Conferência de Estocolmo, com o objetivo de conscientizar a sociedade e assim consentir as necessidades da população presente sem comprometer as gerações futuras. Foram abordados diversos temas na conferência de Estocolmo, estando presente nas discussões mais de 400 instituições governamentais e não governamentais e teve participação de 113 países.

Para comentar o motivo da conferência de Estocolmo, Machado (2006), explana:

Preocupados com o futuro do planeta, a Organização das Nações Unidas (ONU), juntamente com os Estados e a comunidade científica, realizou a Primeira Conferência Mundial sobre o Homem e o Meio Ambiente, visando amenizar a problemática: homem versus natureza. Esse evento ocorreu nos dias 5 a 16 de junho do ano de 1972, na capital sueca, Estocolmo (Machado, 2006).

Essa conferência foi de grande importância para controlar o uso dos recursos naturais pelo homem, sendo que parte destes recursos além de não serem renováveis, quando extraídos da natureza em grandes quantidades, deixam um vazio, cujas consequências virão nas gerações futuras.

Outro evento ambiental foi a Conferência das Nações Unidas sobre o Meio Ambiente e Desenvolvimento, realizada entre os dias 3 e 14 de Junho de 1992, na cidade do Rio de Janeiro, Brasil. O evento conhecido como ECO-92 ou Rio-92, fez um balanço dos problemas existentes e dos progressos realizados, elaborando documentos importantes que continuam sendo referência para as discussões ambientais.

A ECO-92 contou também com um grande número de organizações não governamentais (ONGs), que realizaram de forma equivalente o fórum global, que aprovou a Carta da Terra. Conforme esse documento, os países ricos têm maior responsabilidade na preservação do planeta. 
Durante a ECO-92 duas importantes convenções foram abonadas: uma sobre biodiversidade e outra sobre mudanças climáticas. Outro resultado de essencial importância foi a assinatura da Agenda 21, um plano de ações com metas para a melhoria das condições ambientais do planeta.

Sobre essa conferência, Macieira \& Cerqueira (2014), assim se posicionam:

A maioria dos países decidiu realizar uma grande conferência internacional com o intuito de discutir a preservação ambiental, pois diante desse cenário estava mais do que clara a necessidade de se enfrentar a questão ambiental, coibindo as práticas que, (...) estavam causando danos irreparáveis à saúde, à vida humana e ao meio ambiente.

Tal conferência foi designada oficialmente de Conferência das Nações Unidas sobre Meio Ambiente e Desenvolvimento Sustentável, nomeada de Eco-92, realizada no Rio de Janeiro, em 1992.

Dez anos após a Rio-92, as Nações Unidas novamente patrocinaram, em Agosto de 2002, uma reunião global em Johanesburgo, África do Sul. A Cúpula Mundial deste ano, nomeada de Rio+10, que reuniu representantes de 189 países para debater a preservação do meio ambiente, saneamento básico, saúde, fornecimento de água, entre outros fatores. Um dos pontos mais importantes da conferência foi a busca por medidas para diminuir em 50\%, o número de pessoas que vivem abaixo da linha de pobreza.

No entanto, os resultados da Rio+10 não foram muito expressivos, os países desenvolvidos não cancelaram as dívidas das nações mais pobres, tendo poucos resultados positivos sendo assim referente ao abastecimento de água. Os países concordaram com a meta de diminuir pela metade, o número de pessoas que não tinha acesso à água potável nem a saneamento básico até 2015 .

A Rio+20 foi uma Conferência das Nações Unidas sobre Desenvolvimento Sustentável, que aconteceu na cidade do Rio de Janeiro de 13 a 22 de Junho de 2012, na qual participaram líderes dos 193 países que fazem parte da ONU.

Foram discutidos temas como o balanço do que foi feito nos últimos 20 anos em relação ao meio ambiente, a importância e os processos da Economia Verde, ações para garantir o desenvolvimento sustentável do planeta, modos de eliminar a pobreza, a governança internacional no campo do desenvolvimento sustentável.

O principal objetivo da Rio+20 foi restaurar e reafirmar a participação dos líderes dos países com relação ao desenvolvimento sustentável no planeta, sendo, portanto uma segunda etapa da Cúpula da Terra (ECO-92).

Infelizmente o resultado da Rio+20 não foi o esperado. $\mathrm{O}$ documento final apresentou várias finalidades e joga para os próximos anos a definição de medidas práticas para garantir o amparo do meio ambiente. Muitos analistas disseram que a crise econômica mundial, principalmente nos Estados Unidos e na Europa, danificou as negociações.

\section{Contabilização de eventos ambientais}

Segundo Ribeiro (2006, p.48), a Contabilidade Ambiental, bem como seus elementos possui características bem peculiares, trazendo informações sobre os conceitos e as características desses elementos, podendo ser mensurados e contabilizados.

Quando há ativos, receitas e investimentos ambientais nas demonstrações da empresa, pode se fortalecer pela transparência da responsabilidade social para a sociedade e o meio ambiente. Já a evidenciação de passivo, as despesas e os custos ambientais podem ser abrangidos como degradação provocada pela empresa, principalmente se forem ressarcimentos provisórias ou multas.

\section{a. Ativos e passivos ambientais}

Os ativos ambientais representam os toques dos insumos, peças e acessórios usados no processo de eliminação de poluição e também com investimentos em máquinas, com a finalidade de diminuir os impactos ambientais.

A assimilação dos ativos ambientais é utilizada em negociações, avaliações, transferências, fusões e aquisições entre empresas, comprovando-se a viabilidade legal, e estão incluídos com investimentos em tecnologias, matérias primas e processos de cautela, contenção, diminuição ou cancelamento de aspectos poluentes ou que representam riscos ao meio ambiente e a saúde dos trabalhadores.

As características dos ativos ambientais são desiguais de uma empresa para outra, pois a diferença entre as atividades econômicas deve 
envolver todos os bens utilizados no controle e preservação do meio ambiente.

Abordando o assunto ativo ambiental, o conceito indicado por Ribeiro (2010, p.61) é:

Os ativos ambientais são constituídos por todos os bens e direitos possuídos pelas empresas, que tenham capacidade de geração de benefícios econômicos em períodos futuros e que visem à preservação, proteção e recuperação ambiental (Ribeiro,2010, p.61).

Passivo ambiental se menciona a toda obrigação adquirida voluntária ou involuntariamente proposta à aplicação em ações de controle em razão da necessidade de preservar o meio ambiente, desde que estas tenham ocorrido no passado ou permaneçam ocorrendo no presente, e que delas ocorra à utilização futura ou presente de ativos. Na opinião do IBRACON (1996, p.5):

O passivo ambiental pode ser conceituado como toda agressão que se praticou/pratica contra o meio ambiente e consiste no valor de investimentos necessários para reabilitá-lo, bem como multas e indenizações em potencial (IBRACON, 1996, p.5).

Para as empresas o passivo ambiental simula risco financeiro, além de custos para manutenção, e a diminuição do patrimônio líquido de forma que, empresas que possuem um passivo ambiental muito elevado acabam perdendo valor no mercado e lucratividade.

Segundo Paiva (2003), em sua origem, podese entender essas obrigações como passivos ambientais, de duas formas: passivos ambientais normais e passivos ambientais anormais.

Os passivos ambientais normais são aqueles que podem ser controlados, que há alguma forma de prevenir e mensurar sendo decorrentes do processo produtivo, onde sua cautela e mensuração seriam possíveis. Exemplo citado por Paiva (2003) refere-se aos pneus, grandes poluidores quando de seu descarte ao final do ciclo de vida, por se transformarem em locais para reprodução de insetos transmissores de doenças por serem incendiados poluindo $\mathrm{o}$ ar. Atualmente são reaproveitados, gerando a borracha desvulcanizada em pó, destinada ao mercado de produtos novos, como pneus e pisos.

Os passivos ambientais anormais são aqueles em que a empresa não tem como prever, originários de sinistros ou acidentes. Outro exemplo citado por Paiva (2003) exemplifica-se com um acidente ocorrido em um reservatório de material tóxico ou altamente poluente provocado por raio, terremoto, furacão ou outro evento aleatório.

\section{b. Despesas, receitas e custos ambientais}

Despesas ambientais são todos os gastos abrangidos com a contabilidade ambiental consumidos no período e usado na área administrativa. Quando aproveitados diretamente na produção, estes gastos são considerados como custo, e se forem aplicados de forma indireta são chamados de despesa.

As despesas ambientais dividem-se em despesas operacionais e despesas não operacionais. As operacionais são a depreciação de equipamentos, pessoal envolvido na produção, descontaminação entre outros, e devem ser evidenciadas na demonstração do resultado do exercício, enquanto as não operacionais são as que transcorrem fora da atividade principal da empresa como: multas, sanções e compensações de terceiros.

De acordo com Iudícibus \& Marion (2000, p.173) as receitas ambientais decorrem de prestação de serviços especializados em gestão ambiental e pode ser definida como o acréscimo de benefícios econômicos durante o período contábil na forma de entrada de ativos ou decréscimo de exigibilidade e que redunda num acréscimo do patrimônio líquido.

A Receita constitui um retorno de valores, uma recuperação de investimentos, renda originada por um bem patrimonial, comprovando a parte positiva nos demonstrativos de resultados.

Os custos ambientais estão relacionados a indenizar os danos ambientais gerados pela população e com a valorização econômica ambiental, ajuda na priorização dos atos ambientais.

Segundo Carvalho (2000, p.15) os custos ambientais compreendem todos aqueles gasto relacionados direta ou indiretamente com a proteção do meio ambiente e que serão ativados em função de sua vida útil.

Os custos ambientais podem ser classificados como custos internos e custos externos. Custos internos são aqueles contabilizados ao longo do processo produtivo, estando relacionados com a determinação do preço de venda dos produtos, por exemplo, a mão de obra, a matéria prima, etc. Custos externos são gerados pelo impacto da 
atividade da empresa no meio ambiente e na sociedade, por exemplo, custos com tratamento de doenças causado pela poluição do ar.

\section{Balanço Social}

As primeiras origens do Balanço Social se deram na década de 60 , como forma de repúdio à guerra do Vietnã. Foi uma forma de boicote à aquisição de produtos e ações de empresas que de alguma forma estivessem ligadas a esse conflito, a utilização de armas, tais como bombas, gases paralisantes, produzidos pelas empresas norteamericanas, que prejudicavam o homem e o meio ambiente, fazendo com que as organizações adotassem uma nova conduta empresarial, porém foi instituído na França, em 1977.

Segundo Ribeiro (2006, p.9), visando reagir as pressões da sociedade, que exigia nova postura ética, as empresas passaram a prestar contas de suas ações com o intuito de melhorar a imagem focando na questão ambiental junto a consumidores e acionistas. Sobretudo passou a ser captado pela sociedade afim de seus direitos, ter garantia da continuidade de vida saudável e poder exigir que os recursos utilizados pelos governantes possam produzir benefícios para a população.

Com as constantes mudanças houve uma necessidade de observar com maior relevância o meio ambiente, à noção de responsabilidade se evidenciou pela primeira vez nos Estados Unidos na década de 1930 (Tinoco; 2011 p.5), em que as empresas públicas e privadas, começaram a observar que faltava algo para somar às empresas, para que o meio ambiente tivesse importância, como uma manifestação vinda da sociedade, houve a imprescindibilidade de criar um método para gerar nova postura ética.

Primeiramente foi nomeado como Balanço Social, pois nada mais era que um demonstrativo publicado pelas empresas reunindo informações sociais. Com o passar do tempo foram incluindo alguns pontos como, responsabilidade social da empresa, a sua participação ativa com o meio ambiente e concluindo com o valor adicionado a economia local (DVA), contando com todos esses fatos, nos dias de hoje é intitulado Balanço Socioambiental.

\section{Obrigatoriedade do Balanço Socioambiental}

Pela lei Francesa, desde 1979 é obrigatória a elaboração do Balanço Social das empresas com um quadro maior que 300 funcionários (Tinoco,
2008. p. 90). Vários países seguiram seus passos, destacando, Alemanha, Holanda, Bélgica, Espanha, Portugal e Inglaterra. Por tanto no Brasil, a Associação dos Dirigentes Cristãos de Empresas - ADCE, que previam princípios de função social, por meio de seus trabalhadores e da comunidade local, organizou seu $2^{\circ}$ Encontro Nacional, discutindo o tema, em 1977. A ADCE, em abril de 1980, promoveu um Seminário Internacional de Balanço Social, em São Paulo, onde se encontraram palestrantes da Alemanha, Argentina, Chile, Colômbia, Espanha e Uruguai.

Segundo Ribeiro (2006, p.11), algumas iniciativas pioneiras referentes à publicação do Balanço Social, foram:

1984: a Empresa Nitrofértil produz seu Balanço Social, reconhecido como o primeiro publicado no Brasil em 1886: É lançado o Balanço Social do mercado de capitais, patrocinado pelo Comitê de Divulgação do Mercado de Capitais- Codimec; 1991: a Telebrás a primeira Demonstração de Valor Adicionado;1992: a extinta Companhia Metropolitana de Transportes Coletivos CMTC e o Banespa publicam sua Demonstração de Valor Adicionado;1993: A Febraban elabora a primeira Demonstração do Valor Adicionado no setor bancário (Ribeiro, 2006, p.11).

Desde então várias leis foram criadas, em destaque o deputado Valmir Campello, que 1991 que enviou para o Congresso Nacional um projeto para votação da obrigatoriedade da publicação do Balanço Social, no Brasil; embora não tenha sido discutido, e nem votado. Em 1996 ocorreu uma iniciativa do Instituto Brasileiro de Análises Sociais Econômicas - IBASE, onde o sociólogo Herbert de Souza, até então presidente do instituto, que buscou resgatar o Balanço social para o país. Neste tempo foi lançado um modelo que foi aceito e exercido pelas empresas brasileiras, com o passar do tempo teria sido aprimorado, e hoje o mais utilizado no Brasil. Em 1997, as deputadas Sandra Starling, Marta Suplicy e Maria Conceição Tavares desenvolveram um projeto de Lei $\mathrm{n}^{\circ}$. 3.116 como o intuito da obrigação das empresas publicarem o Balanço Social. Entretanto o projeto foi arquivado.

Observa-se que a iniciativa de estipular o Balanço Socioambiental no Brasil, não é atual, e o aspecto mais polêmico é essa questão, da obrigatoriedade. De acordo com Ribeiro (2006, p.13), apresenta que alguns entendiam a 
relevância de impor a publicação, já havia outros que acreditavam que deveria ser deixado à escolha da entidade. Por questão de responsabilidade social e não por obrigatoriedade, as empresas nos últimos anos além de necessárias têm publicados seus Balanços Socioambientais juntamente com as demonstrações contábeis em jornais e sites, tentando esclarecer sua contribuição para a sustentabilidade.

Mesmo não sendo obrigatório, existem empresas que tem satisfação em publicar suas demonstrações para influência a outras empresas na elaboração de seus balanços, que trazem relatórios importantes para seus colaboradores e sociedade.

A necessidade tem estimulado os governantes na elaboração do Balanço Socioambiental pelas empresas que ocupam o território sob sua responsabilidade.

Ribeiro explana sobre a seguinte lei:

A lei $\mathrm{n}^{\circ}$ 8118/1998, do município de Porto Alegre é exemplo disso, pelo qual retribuí com o Selo de cidadania concedido às empresas que com mais de 20 funcionários apresentarem o Balanço Socioambiental, dentro das regras designadas na própria lei (Ribeiro; 2006 p.14.)

Segundo normas estabelecidas pela NBC T 15 , nenhuma empresa está obrigada a exercer ou divulgar informações de natureza social ou ambiental, porém quem optar por sua execução deverá seguir regras estipuladas.

Foi Publicado no Diário Oficial da União de 6 de setembro de 2004, que o Conselho Federal de Contabilidade (CFC), introduzia a Norma Brasileira de Contabilidade (NBC T 15), sobre a elaboração do Balanço Socioambiental. As Normas Brasileiras de Contabilidade estabeleceram procedimentos para evidenciação de informações de natureza social e ambiental, com o intuito de comprovar à sociedade a colaboração e a responsabilidade social da empresa, em concordância com os Princípios Fundamentais da Contabilidade, que são regulamentadas pela Resolução CFC No 751, 29 de dezembro de 1993 (Portal De Contabilidade, $\mathrm{S} / \mathrm{d})$.

A interação com o meio ambiente, o convívio da entidade com o ambiente externo, a geração e distribuição de riquezas e recursos humanos é assim que a NBC T 15 define informação de natureza social e ambiental.
Deve estar contido um relato preciso em informações de nível educacional, formal, social, medica, treinamento, sexo, assistência previdenciária e outros. Esses relatos são importantes para saber a capacidade de absorção de mão-de-obra e mercado, e uma forma de impulsionar e instruir os colaboradores com uma qualidade de vida elevada.

\section{Demonstração de Valor Adicionado}

De acordo com Ribeiro (2006, p.19), referente a indicadores ambientais, que ao captar recursos renováveis ou não do meio ambiente, a organização utiliza do patrimônio da humanidade. A entidade está introduzida na sociedade, em um ecossistema e por isso a informação é de suma importância e deve estar contida nas demonstrações contábeis.

Uma das formas que aumentam a capacidade de analisar o desempenho econômico e social das entidades é através do valor que é associado pelas empresas aos bens e serviços adquiridos de terceiros, sendo o valor adicionado (Tinoco, 2008, p.98).

A Demonstração de Valor Adicionado (DVA) é um componente de alta relevância, essa demonstração surgiu na Europa e é utilizada em muitos países, como Inglaterra, Espanha, Portugal, França e Itália. Por enquadrar informações econômicas e sociais, por cada vez mais ser requisitada em nível internacional, por recomendações da Organização das Nações Unidas (Costa; 2012 p.189).

Segundo Tinoco (2008, p.99) algumas iniciativas pioneiras na elaboração da Demonstração do Valor Adicionado:

Atualmente, algumas empresas (poucas ainda) já vêm publicando a DVA, no Brasil. O início deu-se a partir das publicações pioneiras da Telebrás e de algumas de suas controladoras, no exercício de 1990; da (extinta) Cia. Municipal de Transporte Coletivo (CMTC) de São Paulo em 1991 e do Banespa no exercício de 1992 (Tinoco, 2008 p.99).

A DVA é parte do Balanço Social e foi constituída para evidenciar fatos relatados, de função informativa sobre quanto a empresa adquiriu de recursos, e como foi feita a distribuição do valor adicionado entre a remuneração dos colaboradores e como foi realizado o uso de capital de terceiros, tributos pagos ao governo, remuneração do capital próprio. Normalmente, as demonstrações 
contábeis não influenciam no papel social e econômico que as empresas adotam na região em que atuam; e o diferencial da DVA é justamente esse, o de evidenciar os destinatários da riqueza gerada além dos acionistas. Em uma prefeitura, por exemplo, é a sociedade que tem maior interesse em conhecer sobre esse retorno.

A responsabilidade técnica obtida nas informações contábeis da DVA é de responsabilidade de contadores registrados no Conselho Regional de Contabilidade (Costa, 2012, p.191).

Pode-se constatar que o Balanço Socioambiental é um instrumento capaz de gerar informações de empresas e entidades públicas ou privadas, e com o intuito de demonstrar e divulgar as atividades sociais da entidade, junto com o funcionamento econômico-financeiro e ambiental. Sendo assim a sociedade pode compreender melhor o que se passa dentro de uma entidade desde cargos, número de funcionários e seu comportamento com o meio ambiente.

É direito da sociedade, conhecer os relatos contábeis, entretanto detalhadas e o quantitativos em valores socioeconômicos em forma de folha de pagamentos de funcionários e terceiros encargos sociais, restituição e indenização, com maior relevância no caso de prefeituras. Por base de registros extraídos da contabilidade, o Balanço Socioambiental, é alicerçado no princípio contábil da competência.

\section{Balanço Social Modelo IBASE}

O Instituto Brasileiro de Análises Sociais e Econômicas - IBASE é uma organização sem fins lucrativos, de cidadania ativa. Em 1981 foi constituída por Herbert de Souza, o Betinho, e seus companheiros de exílio Carlos Afonso e Marcos Arruda, após a anistia política. O IBASE está ligado à democratização do Brasil, em privada a emergência da cidadania e a constituição de sociedade civil brasileira das últimas três décadas.

Segundo o site do IBASE, ele se porta mais como ator na sociedade civil, autônoma e pública do que instituição, e tornou-se símbolo de cidadania no Brasil ao comandar a Ação da Cidadania contra a Fome, a Miséria e pela Vida, distinguida como a campanha contra a fome. Sempre apontando movimentos políticos e culturais, que tenham os direitos, a cidadania, a democracia e a sustentabilidade socioambiental como suas agendas, é o que dirige o IBASE desde a sua fundação.

Quando o IBASE preparou um modelo único e simplificado de Balanço em 1997, o sociólogo Betinho começou uma campanha para exposição das empresas. O projeto obteve vários apoios importantes, realizando Balanços Sociais anuais. Como estímulo a instituição lançou o selo social IBASE/Betinho, a todas as empresas que publicassem seus balanços no modelo sugerido pela instituição. Ainda é disponível o modelo de Balanço Social para quem desejar usar, mais o selo foi pendente desde 2008. Ainda em 2008 foi lançado pelo IBASE o livro "Balanço Social, o desafio da Transparência".

\section{Balanço social modelo IBASE - subdivisões}

A Estrutura do Balanço Social exibe dados e informações de dois exercícios anuais por meio de uma tabela bem simples e direta, que deve ser publicada e divulgada. Seus principais indicadores sociais são os de Base de Cálculo, Indicadores Sociais Internos, Indicadores Sociais Externos, Indicadores Ambientais, Indicadores do Corpo Funcional, Informações ressaltantes quanto ao exercício da cidadania empresarial dentre outras informações.

A Base de cálculo, como o próprio nome já diz, é feita por meio das três informações financeiras: receita líquida, resultado operacional e folha de pagamento bruta, que servem de base de cálculo percentual para grande parte das informações e dos dados apresentados, fornecendo informações de impacto dos investimentos nas contas da empresa, além fazer uma comparação entre as empresas e setores ao decorrer dos anos.

Conforme o IBASE, os Indicadores sociais internos, e nesta parte do balanço serão expostos todos os investimentos internos, obrigatórios e voluntários, que a empresa fornece para beneficiar e/ou atender ao corpo funcional (alimentação, encargos sociais compulsórios, previdência privada, saúde, segurança e medicina no trabalho, educação, cultura, capacitação e desenvolvimento profissional, creches ou auxíliocreche, participação nos lucros ou resultados e outros).

Indicadores sociais externos serão fornecidos os investimentos voluntários da empresa, cujo público-alvo é a sociedade em geral (projetos e iniciativas nas áreas de educação, cultura, saúde e saneamento, esporte, combate à fome e segurança 
alimentar, pagamento de tributos e outros). São as ações sociais privadas desenvolvidas por empresas tendo em vista à sociedade, direta ou indiretamente, com os objetivos ou interesses das corporações.

Indicadores ambientais são demonstrados os investimentos da empresa para abrandar ou compensar seus impactos ambientais e também aqueles que têm o foco de melhorar a qualidade ambiental da produção/operação da empresa, seja por meio de inovação tecnológica, seja por programas internos de educação ambiental.

Indicadores do corpo funcional já nesta parte do balanço contêm as informações que identificam de que forma se dá o relacionamento da empresa com seu público interno, utilização do trabalho terceirizado, número de estagiários (as), valorização da diversidade, (negros(as), mulheres, faixa etária e pessoas com deficiência) e participação de grupos que de acordo com a história são discriminados no país em cargos de chefia e gerência a empresa (mulheres e negros).

Informações relevantes quanto ao exercício da cidadania empresarial, o termo utilizado nesta parte do modelo (cidadania empresarial) refere-se à uma série de ações relacionadas aos públicos que interagem com a empresa, com grande destaque no público interno. Em sua maioria, são indicadores qualitativos que mostram como está a participação interna e a distribuição dos benefícios. Também aparecem nesta parte do balanço algumas das diretrizes e dos processos desenvolvidos na empresa que estão relacionados às políticas e práticas de gestão da responsabilidade social corporativa.

Outras informações, este espaço é reservado e vastamente utilizado pelas empresas para expressar outras informações que sejam relevantes para a compreensão de suas práticas sociais e ambientais. De acordo com o IBASE, as empresas que solicitam o "Selo Balanço Social IBASE/Betinho" devem apresentar suas declarações de não utilização de mão-de-obra infantil ou de trabalho análogo ao escravo ou ofensivo; seu não envolvimento com prostituição ou exploração sexual infantil ou adolescente; seu não envolvimento com corrupção; e sua obrigação com a valorização e o respeito à diversidade. Deve, também, proporcionar sua identificação e classificação, informar sua identificação (razão social e CNPJ), além de nome, telefone e correio eletrônico da pessoa responsável pelas informações.

\section{Material e Métodos}

A metodologia utilizada para pesquisa é de ordem descritiva, qualitativa e quantitativa, sucedida mediante estudo de caso, contendo informações do ano 2014.

As informações foram obtidas por meio de coleta de dados e relatórios contábeis, registros dos departamentos envolvidos, depoimentos e entrevistas informais, e auxilio da professora orientadora.

Foi objeto de estudo, as informações da Prefeitura de Novo Brasil, localizada a noroeste do Estado de Goiás, com emancipação em 1958. O município possui uma área de 649,954 km, e sua população é estimada em 2014 é de 3.392 habitantes segundo o Instituto Brasileiro de Geografia e Estatística (IBGE, 2014).

A escolha da prefeitura é fundamentada pela facilidade de coleta de dados e especialmente pelo interesse acadêmico em relatar em estudo socioambiental na região. Todas as informações referentes a valores foram obtidos dentro da contabilidade, arrecadação, Recursos humanos, Jurídico, Secretaria do Meio Ambiente.

O modelo de Balanço Socioambiental estabelecido para a inserção foi o modelo do Instituto Brasileiro de Análises Sociais e Econômicas - IBASE, por ser o mais utilizado no Brasil além de todos os itens exigidos pela norma do Conselho Federal de Contabilidade. Entretanto, houve a imprescindibilidade de realizar adaptações para demonstrações mais clareza de valores, visto que a prefeitura de Novo Brasil ainda não tem seu Balanço executado, sendo assim, eventualmente não possui controle de algumas informações relatadas.

A prefeitura de Novo Brasil conta atualmente com um quadro de 226 funcionários, comissionados e efetivos, atribuído em oito secretarias: Administração e Recursos Humanos; Ação Social, Trabalho e Habitação; Cultura Desporto, Lazer e Juventude; Educação; Planejamento, Finanças, Agricultura e Com. e Indústria; Meio ambiente e Turismo; Saúde; Infra estrutura, Transporte, Obras Públicas e Serviços.

Objetiva-se a apresentar resultados deste estudo à comunidade, com base que a transparência é primordial para entidades públicas. Estima-se que o estudo possa ter relevância e ser aplicado em diversas prefeituras após as devidas apropriações. 
Serão apresentados a seguir itens passiveis de pesquisa com base no modelo escolhido.

Quadro 1. Apresentação da entidade

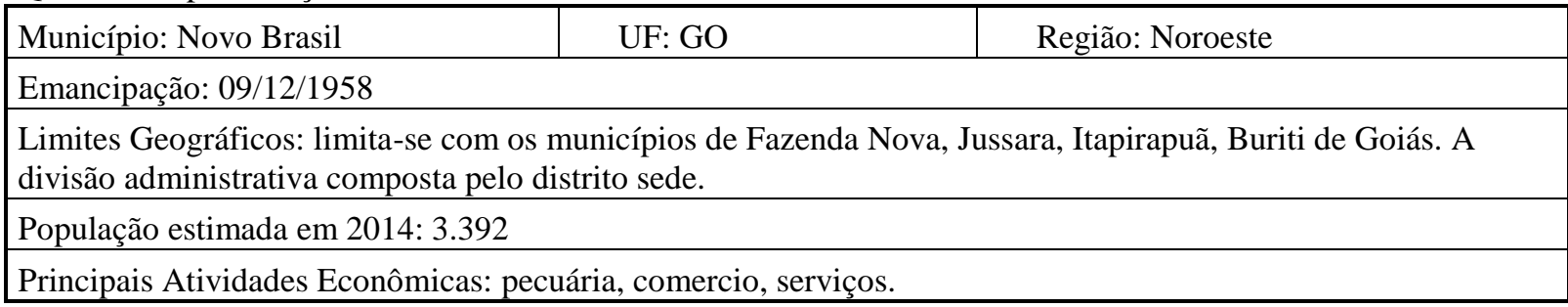

Fonte: Instituto Brasileiro de Geografia e Estatística (2014)

Com base no IBGE (2014), no ano de 2010 o município apresentou um índice de desenvolvimento humano (IDHM) de 0,699. O município de Novo Brasil, em 2012 apresentou o PIB per capita a preços correntes de $12.364,83$ reais, e um PIB a preços correntes de 42.288 reais. O Valor adicionado bruto da agropecuária a preços correntes, em 2012 foi de 16.929 mil reais; o Valor adicionado bruto da indústria a preços correntes foi de 2.970 mil reais; e o Valor adicionado bruto dos serviços a preço corrente foi de 20.366 mil reais, sendo assim, o segmento de maior relevância no município é o de serviços.

Ainda de acordo com os dados do IBGE (2014), no referido ano o município possuía 3.392 habitantes, sendo que 1.819 são do sexo masculino e 1.700 do sexo feminino e, a população alfabetizada se dá no total de 2.919 , representando a maioria da população. A sua Densidade demográfica foi de $5,41 \mathrm{hab} . / \mathrm{km}^{2}$, um dado relativamente baixo. Com dados do Tribunal Regional Eleitora de Goiás (TRE-GO), em março de 2013, representando 0,08\% do estado, o município possuía 3.410 eleitores.

\section{Resultados e Discussão}

\section{Indicadores Monetários}

De acordo com Tinoco (2008), os indicadores monetários contêm informações gerais do resultado operacional, onde se sobressaem as contas de despesas e receitas distribuídas em indicadores laborais como: folha de pagamento de funcionário e indicadores sociais externos por meio dos gastos com saúde, educação, assistência social e previdência.

Receita Pública é a entrada de recursos que integralizam o patrimônio publico, onde toda arrecadação de rendas devem ser autorizadas pela Constituição Federal. Em outro sentido, receitas são entradas que acrescentam ao patrimônio com todas as quantias recebidas pelos cofres públicos.
Despesa Pública é a aplicação em dinheiro com recursos do Município para investir no próprio desenvolvimento, a fim de atender uma necessidade da coletividade, desde que esteja prevista no orçamento.

Folha de Pagamento é um documento feito por todas as pessoas jurídicas que possuam funcionários.

De acordo com o site do Tribunal de Contas dos Municípios (TCM), Novo Brasil-GO em 2014 teve uma receita de $12.642 .374,44$ de reais, distribuídos entre Fundo Municipal de Assistência Social, Fundo Municipal de Saúde, Fundo de Manutenção e Desenvolvimento da Educação Básica, Fundo de Previdência Social e Poder Executivo. Receitas são compostas pelos impostos e taxas reclusos diretamente pela Prefeitura e de recursos do Governo Estadual e Federal, que repassam parte dos impostos que recebem ao município.

Pela análise dos dados é possível constatar que o Poder Executivo teve o montante maior que todos os outros, totalizando $\mathrm{R} \$ 9.815 .718,52$ no ano de 2014 (Tabela 1). O Fundo Municipal de Assistência Social teve o menor valor no montante, com um valor de 141.209,97 reais. Os valores são consideravelmente exorbitantes, mas por consequência são valores que servem para custear despesas públicas; porém o Poder Executivo tem mais investimentos a serem feitos e é o departamento que tem mais gasto com pessoal, comparado com o restante dos departamentos incluindo a Assistência Social, que obteve o menor montante.

Despesas são contas a pagar, como o funcionalismo público, manutenção, construção, investimentos em saúde, educação, assistência social, dentre outros. Segundo o TCM o valor total de Despesas em 2014 foi de R\$ 11.755.796,30. 
Tabela 1. Indicadores gerais do resultado operacional das receitas

\begin{tabular}{lccccc}
\hline Mês & FMAS & FMS & $\begin{array}{c}\text { FUNFEF/ } \\
\text { FUNDEB }\end{array}$ & FPS & Poder Executivo \\
\hline Janeiro & $\mathrm{R} \$ 17.398,05$ & $\mathrm{R} \$ 92.977,50$ & $\mathrm{R} \$ 53.446,44$ & $\mathrm{R} \$ 24.357,08$ & $\mathrm{R} \$ 1.033 .434,32$ \\
Fevereiro & $\mathrm{R} \$ 35.976,32$ & $\mathrm{R} \$ 63.118,64$ & $\mathrm{R} \$ 57.397,69$ & $\mathrm{R} \$ 60.658,72$ & $\mathrm{R} \$ 757.014,29$ \\
Março & $\mathrm{R} \$ 7.847,80$ & $\mathrm{R} \$ 91.924,14$ & $\mathrm{R} \$ 54.710,64$ & $\mathrm{R} \$ 14.866,76$ & $\mathrm{R} \$ 590.752,74$ \\
Abril & $\mathrm{R} \$ 6.824,27$ & $\mathrm{R} \$ 61.801,35$ & $\mathrm{R} \$ 61.931,26$ & $\mathrm{R} \$ 84.413,95$ & $\mathrm{R} \$ 817.837,86$ \\
Maio & $\mathrm{R} \$ 7.972,27$ & $\mathrm{R} \$ 77.415,41$ & $\mathrm{R} \$ 65.839,45$ & $\mathrm{R} \$ 61.603,96$ & $\mathrm{R} \$ 795.231,51$ \\
Junho & $\mathrm{R} \$ 99,10$ & $\mathrm{R} \$ 44.860,29$ & $\mathrm{R} \$ 60.232,36$ & $\mathrm{R} \$ 47.731,28$ & $\mathrm{R} \$ 644.985,56$ \\
Julho & $\mathrm{R} \$ 16.017,45$ & $\mathrm{R} \$ 104.310,23$ & $\mathrm{R} \$ 64.114,46$ & $\mathrm{R} \$ 50.471,88$ & $\mathrm{R} \$ 623.107,65$ \\
Agosto & $\mathrm{R} \$ 7.321,02$ & $\mathrm{R} \$ 86.373,09$ & $\mathrm{R} \$ 67.482,14$ & $\mathrm{R} \$ 95.121,22$ & $\mathrm{R} \$ 709.825,16$ \\
Setembro & $\mathrm{R} \$ 88,67$ & $\mathrm{R} \$ 322.446,37$ & $\mathrm{R} \$ 71.588,75$ & $\mathrm{R} \$ 11.025,13$ & $\mathrm{R} \$ 860.360,31$ \\
Outubro & $\mathrm{R} \$ 24.668,77$ & $\mathrm{R} \$ 74.612,61$ & $\mathrm{R} \$ 64.990,77$ & $\mathrm{R} \$ 41.788,47$ & $\mathrm{R} \$ 627.454,88$ \\
Novembro & $\mathrm{R} \$ 15.694,17$ & $\mathrm{R} \$ 119.146,63$ & $\mathrm{R} \$ 66.373,44$ & $\mathrm{R} \$ 70.838,85$ & $\mathrm{R} \$ 767.892,26$ \\
Dezembro & $\mathrm{R} \$ 1.302,08$ & $\mathrm{R} \$ 133.468,07$ & $\mathrm{R} \$ 76.298,13$ & $\mathrm{R} \$ 85.708,77$ & $\mathrm{R} \$ 1.587 .821,98$ \\
\hline Total & $\mathrm{R} \$ 141.209,97$ & $\mathrm{R} \$ 1.272 .454,3$ & $\mathrm{R} \$ 764.405,53$ & $\mathrm{R} \$ 648.586,07$ & $\mathrm{R} \$ 9.815 .718,52$ \\
\hline
\end{tabular}

Fonte: Tribunal de Contas do Município

Tabela 2 - Indicadores gerais do resultado operacional das despesas.

\begin{tabular}{lccc}
\hline Mês & FMAS & FMDCA & FMS \\
\hline Janeiro & $\mathrm{R} \$ 24.130,20$ & $\mathrm{R} \$ 355,48$ & $\mathrm{R} \$ 116.582,92$ \\
Fevereiro & $\mathrm{R} \$ 26.592,27$ & $\mathrm{R} \$ 0,00$ & $\mathrm{R} \$ 362.732,21$ \\
Março & $\mathrm{R} \$ 29.548,13$ & $\mathrm{R} \$ 400,00$ & $\mathrm{R} \$ 216.838,76$ \\
Abril & $\mathrm{R} \$ 43.875,73$ & $\mathrm{R} \$ 0,00$ & $\mathrm{R} \$ 377.863,51$ \\
Maio & $\mathrm{R} \$ 42.426,91$ & $\mathrm{R} \$ 0,00$ & $\mathrm{R} \$ 290.913,27$ \\
Junho & $\mathrm{R} \$ 35.331,86$ & $\mathrm{R} \$ 0,00$ & $\mathrm{R} \$ 233.425,41$ \\
Julho & $\mathrm{R} \$ 35.650,41$ & $\mathrm{R} \$ 0,00$ & $\mathrm{R} \$ 357.096,02$ \\
Agosto & $\mathrm{R} \$ 38.909,14$ & $\mathrm{R} \$ 0,00$ & $\mathrm{R} \$ 296.859,62$ \\
Setembro & $\mathrm{R} \$ 23.460,78$ & $\mathrm{R} \$ 0,00$ & $\mathrm{R} \$ 378.532,72$ \\
Outubro & $\mathrm{R} \$ 35.123,05$ & $\mathrm{R} \$ 0,00$ & $\mathrm{R} \$ 362.124,69$ \\
Novembro & $\mathrm{R} \$ 35.910,88$ & $\mathrm{R} \$ 0,00$ & $\mathrm{R} \$ 345.949,75$ \\
Dezembro & $\mathrm{R} \$ 53.736,34$ & $\mathrm{R} \$ 0,00$ & $\mathrm{R} \$ 593.665,05$ \\
\hline Total & $\mathrm{R} \$ 424.695,70$ & $\mathrm{R} \$ 755,48$ & $\mathrm{R} \$ 3.932 .583,93$ \\
\hline
\end{tabular}

Fonte: Tribunal de Contas dos Municípios.

Foram distribuídos entre Fundo Municipal dos Direitos Da Criança e do Adolescente, Fundo Municipal de Assistência Social, Fundo Municipal de Saúde, Fundo de Manutenção e Desenvolvimento da Educação Básica, Fundo de Previdência Social, Poder Legislativo e Poder Executivo.

O montante que teve maior relevância foi também do Poder Executivo, com R\$
5.460.065,32 (Tabela 3), e o menor gasto foi de $\mathrm{R} \$ 755,48$ do Fundo Municipal dos Direitos Da Criança e do Adolescente (Tabela 2). Como já ressaltado, o Poder Executivo exibe valores altos em relação aos outros, tanto em despesas como receitas, porém por falha das publicações do município não é possível descriminar cada conta. 
Tabela 3 - Indicadores gerais do resultado das despesas

\begin{tabular}{lcccc}
\hline Mês & FUNFEF/ FUNDEB & FPS & Poder Executivo & Poder Legislativo \\
\hline Janeiro & $\mathrm{R} \$ 40.264,96$ & $\mathrm{R} \$ 32.501,01$ & $\mathrm{R} \$ 311.193,31$ & $\mathrm{R} \$ 50.070,12$ \\
Fevereiro & $\mathrm{R} \$ 40.741,49$ & $\mathrm{R} \$ 36.693,84$ & $\mathrm{R} \$ 376.380,94$ & $\mathrm{R} \$ 50.611,76$ \\
Março & $\mathrm{R} \$ 43.766,78$ & $\mathrm{R} \$ 39.722,95$ & $\mathrm{R} \$ 509.218,48$ & $\mathrm{R} \$ 48.315,77$ \\
Abril & $\mathrm{R} \$ 45.409,25$ & $\mathrm{R} \$ 55.246,78$ & $\mathrm{R} \$ 523.284,39$ & $\mathrm{R} \$ 50.422,99$ \\
Maio & $\mathrm{R} \$ 45.322,58$ & $\mathrm{R} \$ 51.967,21$ & $\mathrm{R} \$ 527.652,60$ & $\mathrm{R} \$ 65.395,24$ \\
Junho & $\mathrm{R} \$ 48.765,02$ & $\mathrm{R} \$ 46.033,57$ & $\mathrm{R} \$ 451.595,26$ & $\mathrm{R} \$ 58.174,85$ \\
Julho & $\mathrm{R} \$ 99.112,63$ & $\mathrm{R} \$ 43.265,34$ & $\mathrm{R} \$ 411.345,91$ & $\mathrm{R} \$ 52.167,95$ \\
Agosto & $\mathrm{R} \$ 65.010,71$ & $\mathrm{R} \$ 40.563,00$ & $\mathrm{R} \$ 406.541,50$ & $\mathrm{R} \$ 55.099,51$ \\
Setembro & $\mathrm{R} \$ 94.952,97$ & $\mathrm{R} \$ 45.978,66$ & $\mathrm{R} \$ 377.718,95$ & $\mathrm{R} \$ 58.453,72$ \\
Outubro & $\mathrm{R} \$ 63.810,02$ & $\mathrm{R} \$ 44.496,18$ & $\mathrm{R} \$ 458.422,93$ & $\mathrm{R} \$ 54.391,09$ \\
Novembro & $\mathrm{R} \$ 65.483,73$ & $\mathrm{R} \$ 48.852,36$ & $\mathrm{R} \$ 443.272,87$ & $\mathrm{R} \$ 63.395,75$ \\
Dezembro & $\mathrm{R} \$ 76.743,90$ & $\mathrm{R} \$ 47.046,37$ & $\mathrm{R} \$ 663.438,18$ & $\mathrm{R} \$ 69.445,82$ \\
\hline Total & $\mathrm{R} \$ 729.384,04$ & $\mathrm{R} \$ 532.367,27$ & $\mathrm{R} \$ 5.460 .065,32$ & $\mathrm{R} \$ 675.944,57$ \\
\hline
\end{tabular}

Fonte: Tribunal de Contas dos Municípios.

Tabela 4 - Indicadores gerais do resultado com folha de pagamento

\begin{tabular}{lcccc}
\hline Mês & FMAS & FMS & $\begin{array}{c}\text { FUNFEF/ } \\
\text { FUNDEB }\end{array}$ & Poder Executivo \\
\hline Janeiro & $14.541,84$ & $62.327,40$ & $25.261,45$ & $142.266,80$ \\
Fevereiro & $13.733,42$ & $62.175,73$ & $27.529,05$ & $143.857,58$ \\
Março & $11.113,30$ & $65.252,88$ & $27.272,64$ & $148.350,60$ \\
Abril & $11.354,63$ & 60.383 & $32.315,68$ & $146.209,22$ \\
Maio & $12.199,30$ & $65.148,41$ & $34.458,27$ & $140.686,16$ \\
Junho & $11.113,30$ & $60.743,39$ & $31.521,14$ & $147.390,05$ \\
Julho & $13.529,54$ & $68.381,07$ & $35.509,04$ & 154.320 \\
Agosto & $14.129,54$ & $70.848,08$ & $32.380,90$ & 142.410 .02 \\
Setembro & $11.837,30$ & $74.388,41$ & $31.092,40$ & 151.138 .06 \\
Outubro & $12.797,07$ & $73.977,33$ & 29.593 .46 & $146.938,06$ \\
Novembro & $13.089,04$ & $74.748,80$ & $32.585,03$ & $136.833,13$ \\
Dezembro & $13.841,97$ & $74.037,60$ & 34.614 & $148.958,58$ \\
\hline Total & $153.280,25$ & $812.412,10$ & $374.133,06$ & $1.749 .358,00$ \\
\hline Fonte: Prefeit & & &
\end{tabular}

Fonte: Prefeitura de Novo Brasil (2015).

Os dados da Folha de pagamento foram extraídos do setor de Recursos Humanos da Prefeitura de Novo Brasil - GO, verificando então que o menor montante gasto é com a Assistência Social, R $\$ 153.280,25$, e o maior valor gasto é com o Poder Executivo, R \$1.749.358,00 (Tabela 4.). Folha de Pagamento refere-se a um montante pago a empregados de uma determinada empresa, durante um determinado tempo, e totalizou assim em 2014 um valor $\mathrm{R} \$ 3.089 .183,40$.
Com base nos dados do RH (Recursos humanos), na Folha de Pagamento de cada mês a Previdência Social já está inclusa, portanto não há uma planilha exclusiva pra esse gasto.

Não foram fornecidos os valores dos salários pagos individualmente, somente do montante, o sistema não discrimina os salários individuais apenas o montante e os dados não foram fornecidos pela prefeitura municipal. 
Quadro 2 - indicadores do corpo funcional

\begin{tabular}{|l|c|}
\hline$N^{o}$ de Funcionários (as) no final do exercício & 226 \\
\hline$N^{o}$ de mulheres que trabalham na prefeitura & 150 \\
\hline$N^{o}$ de homens que trabalham na prefeitura & 76 \\
\hline $\mathrm{N}^{\mathrm{o}}$ de funcionários com ensino superior & 51 \\
\hline $\mathrm{N}^{\mathrm{o}}$ de funcionários com ensino médio & 125 \\
\hline $\mathrm{N}^{\mathrm{o}}$ de funcionários com ensino fundamental & 50 \\
\hline
\end{tabular}

Fonte: Prefeitura de Novo Brasil (2015).

Os referentes dados estão armazenados em um sistema próprio, tal esse nomeado Megasoft, usado na prefeitura para processamento de dados e contém informações referentes ao registrar funcionários. $\mathrm{O}$ RH não possui controle referente a idade dos funcionários.

Pode-se claramente observar que a maioria dos funcionários é do sexo feminino, sabendo-se que a igualdade de gêneros é umas primícias para construir uma sociedade com menos preconceitos e menos discriminação, é de fundamental importância para sociedades democráticas e com igualdade. Atualmente as mulheres vêm alcançando grande espaço no mercado de trabalho, assumindo até mesmo tarefas que há alguns anos atrás só podia ser feitas pelos homens.

A prefeitura de Novo Brasil, conta com 226 funcionários, que são distribuídos entre as diferentes áreas, como: Administração, Educação, Biblioteca, Arrecadação, Finanças, Departamento Pessoal, Transporte, Ação Urbana, Merendeiras, Iluminação Pública, Contabilidade, Esporte e Lazer, Controle Interno, Saúde, Secretaria do Meio Ambiente, Prefeito e Vereadores. Pagamentos referentes a funcionários da segurança pública, não está contabilizado, pois são feitos pelo governo estadual.

O quadro de funcionários basicamente não sofre por alterações altamente notáveis, não existindo uma alta rotatividade de funcionários. $\mathrm{O}$ ano iniciou com um número de 225 funcionários e fechou com 226. Não se pode afirmar quantas admissões e demissões aconteceram durante $\mathrm{o}$ período. Agosto e setembro que fechou o mês com 227 colaboradores sendo o maior número comparado com todos os meses; maio teve o menor número com 222 colaboradores.

Na prefeitura, existem cargos que podem ser divididos como comissionados sendo aqueles de ocupação transitória, nomeados em função de confiança, destacando-se entre eles e as autoridades responsáveis; e os efetivos que são de caráter de permanência. Dentre esses colaboradores pode-se afirmar, conforme os dados fornecidos, que 51 (cinquenta e um) colaboradores possuem ensino superior; 126 (cento e vinte e seis) funcionários possuem ensino médio completo; e 50 (cinquenta) possuem somente ensino fundamental. Observase que a maioria dos funcionários possui ensino médio completo com relação aos demais. Seria interessante se a prefeitura investisse em educação e treinamento do quadro de funcionários, assim incentivando a todos que procurem melhorar a cada dia; outra hipótese seria dar preferência à contratação de colaboradores com ensino superior.

Pode-se observar também que o número de funcionários tanto com ensino superior tanto fundamental estão quase em equivalência, com diferença apenas de 1 (um) funcionário.

\section{Indicadores Ambientais}

Cada vez mais, observa-se que a questão ambiental se torna um diferencial competitivo, e tanto empresas públicas como privadas devem tomar iniciativas corretas em relação ao meio ambiente e a sociedade. Para que isso ocorra em sintonia, são necessárias informações viáveis quanto ao valor investido em questões ambientais, dados estes fornecidos pela contabilidade.

O lixo brasileiro é avaliado um dos mais ricos do mundo e sua reciclagem é sustentada pela catação informal. Vivemos em um ambiente onde a natureza é intensamente agredida, toneladas de matérias primas, nativas dos mais diferentes lugares do planeta, são industrializados e consumidos provocando resíduos, que são nomeados de lixo. 
Para dar o seu parecer sobre coleta seletiva, Carvalho explana:

Coleta seletiva de lixo é um processo educacional, social e ambientalista que se baseia no recolhimento de materiais potencialmente recicláveis, separados na origem. Esses materiais após seu beneficiamento e acumulo para comercialização, são vendidas as indústrias recitadoras, que os transformam em novos materiais. A reciclagem é a parte do processo de reaproveitamento do lixo, protegendo o meio ambiente e a saúde da população (Carvalho, 2003 p. 09).

Recentemente na cidade de Novo Brasil existem alguns projetos direcionados ao meio ambiente. Um projeto recente foi a contratação de uma empresa, a Ambiental Consultoria, para prestação de serviço de execução de coleta seletiva e promoção de educação ambiental e sanitária em escolas, bairros e entidades. A referida coleta está em conformidades com o Plano Municipal de Saneamento Básico de Novo Brasil, em fase de implementação.

A coleta seletiva está sob andamento desde 02 de março de 2015, com contrato até 31 de Dezembro de 2015. O preço a ser pago em moeda corrente do país é de 29.000 mil reais, esse valor dividido em 10 parcelas de 2.900 reais.

A execução do trabalho em área urbana é feita todos os dias da semana, duas vezes ao dia no centro comercial, e uma vez nos demais bairros, objetivando a destinação correta dos resíduos recicláveis (papelão, plástico, alumínio, metal e sucata de ferro), o que foi facilitado com a instalação de PEV's (Pontos de Entregas Voluntárias), em modelos de grades para facilitar a separação. É importante salientar que compete ao município a disponibilização de um galpão para armazenamento do material coletado.

O projeto é de iniciativa da prefeitura que oferece a contribuição mínima, cabendo, portanto a cada cidadão fazer sua parte descartando seu lixo de maneira correta, para que na sua destinação seja aproveitado o que for reciclável, e o que não for seja destinado aos aterros.

Os dados aqui apresentados são oriundos do contrato firmado entre o município de Novo Brasil e a empresa privada Ambiental Consultoria situada na cidade de São Luís de Montes Belos - GO.

Outro projeto em andamento é o aterro sanitário, que determina a destinação correta dos resíduos sólidos e o encerramento dos lixões, com a participação de municípios vizinhos, como Jussara, Santa fé de Goiás, Fazenda Nova, Itapirapuã, denominado de Consórcio Intermunicipal de Meio Ambiente (CIMA). O referido consórcio possui como presidente a prefeita Tatiana Santos da cidade Jussara, e como vice-presidente Sebastião Sabino prefeito de Novo Brasil.

Os municípios alegam que é algo caro de se manter, portanto resolveram se unir, pois assim terão facilidade de manter $\mathrm{o}$ aterro e dar a destinação correta dos resíduos sólidos.

$\mathrm{Na}$ primeira instância o projeto não foi aprovado pela FUNASA (Fundação Nacional de Saúde), então o CIMA firmou um termo de ajustamento de conduta (TAC), com o Ministério Público de Goiás, que define as etapas para implantação do aterro sanitário. Em uma dessas etapas o consórcio deverá apresentar um Plano de Recuperação de Área Degradada (PRAD), ou seja, recuperar cada área que hoje funcione como lixão de cada uma das cidades envolvidas no CIMA, outro compromisso é a coleta seletiva, porém Novo Brasil já deu esse passo. O terreno para implantação deste projeto já foi adquirido, no município de Novo Brasil, financiado por todos os municípios envolvidos e aguarda somente burocracias para que saia do papel.

A partir de 2014 nenhuma prefeitura poderá receber recursos federais para projetos de saneamento básico sem elaborar seu Plano Municipal de Saneamento Básico (PMSB). Conforme a Lei $\mathrm{n}^{\circ} 11.445 / 2007$, todas as prefeituras têm por obrigação elaborar o seu plano. O PMSB deve envolver quatro áreas, sendo elas: abastecimento de água potável, esgoto sanitário, manejo de resíduos sólidos, drenagem e manejo das águas pluviais urbanas. Após aprovado, o documento torna-se instrumento de planejamento de gestão participativa, e deve ser elaborado por técnicos da Prefeitura contando com o apoio da sociedade. Depois de discutida com a comunidade, o PMSB deve ser aprovado pela Câmara Municipal.

Diante a aprovação o plano passa a ser referência de desenvolvimento de cada município, atendendo com os serviços de água, coleta e tratamento do esgoto doméstico, limpeza urbana, coleta e destinação adequada do lixo. Conforme dados da prefeitura de Novo Brasil, é gasto com limpeza urbana $\mathrm{R} \$ 100.000,00$ por mês. O prazo para que o Município entregue o 
PMSB é até Dezembro do ano corrente, portanto a prefeitura está tomando providências para que esteja dentro do prazo.

$\mathrm{Na}$ questão responsabilidade ambiental, a prefeitura de Novo Brasil, considera-se um órgão público preocupado e ambientalmente responsável, manuseando suas atividades visando os impactos ambientais, a fim de reduzi-los. Pensando essencialmente no futuro, se sobressaem objetivos importantes a serem realizados, buscando inovações que contribuam com o meio ambiente, como o uso sustentável da água, que hoje já está considerada em uma crise hídrica, projetos de qualidade de vida, educação ambiental e redução de resíduos sólidos.

\section{Conclusão}

Com a análise das informações coletadas, conclui-se que o balanço socioambiental é um instrumento de ampla importância para a gestão das prefeituras. Foi elaborado o Balanço Socioambiental da Prefeitura Municipal de Novo Brasil-GO, com dados fornecidos tanto da entidade quanto pelo portal do TCM - Tribunal de Contas dos Municípios.

Como já previsto, algumas entidades, como essa prefeitura, ainda não se conscientizaram sobre a importância da existência de um Balanço Socioambiental muitas vezes não fornecendo as informações necessárias, minimizando assim os benefícios procedentes dessa produção.

Todas as entidades devem demonstrar com transparência os dados para a sociedade, evidenciando o que tem investido e planejado, contribuindo para uma melhor imagem organizacional e envolvimento social, pois o modelo escolhido se encaixa perfeitamente à prefeitura.

Cabe ressaltar que Novo Brasil - GO foi a segunda cidade da região a realizar essa análise, por influência do primeiro estudo realizado pelos acadêmicos de Ciências Contábeis da Faculdade de Jussara. Como o Balanço socioambiental, é um instrumento importante para evidenciar as informações de impacto social, econômico e ambiental, acredita-se que outras entidades darão continuidade ao estudo fornecido.

\section{Referências Bibliográficas}

Carvalho, S. B. (2003). Análise do processo de Coleta Seletiva de Resíduos Sólidos da Empresa ECO \& BIO- Reciclagem no
Município de São Luís de Montes Belos. 2003. 33f. Monografia de estágio obrigatório - Faculdade de Jussara.

Carvalho, N. L.; Matos, E. R. J.; Moraes, R. O. Contabilidade Ambiental. 2000. Pensar Contábil, Rio de Janeiro, ano III, n. 8.

Costa, C. A. G. Contabilidade ambiental: Contabilidade da gestão ambiental. São Paulo. Atlas, 2012.

IBRACON. Normas e procedimentos de auditoria. NPA 11 - Balanço e Ecologia. 1996. Disponível em: < https://scholar.google.com/scholar_lookup?titl $\mathrm{e}=+$ Normas $+\mathrm{e}+$ procedimentos+de+auditoria \& publication_year $=1996>$. Acesso em 10 set. 2015.

IBGE, Instituto Brasileiro de Geografia e Estatística (2014). Disponível em: $<$ http://www.ibge.gov.br/home/pesquisa/pesq uisa google.shtm?cx $=0097910198137843135$ 49\%3Aonz63jzsr68\&cof=FORID\%3A9\&ie=I SO859\&q=novo+brasil\&sa=Pesquisar\&siteur l=www.ibge.gov.br\%2Fhome\%2F\&ref=www .ibge.gov.br\%2F\&ss=6485j4470363j17.

Iudícibus, S. \& Marion, J. C. (2000) Introdução à Teoria da Contabilidade. $2^{a}$ edição. São Paulo: Atlas, $301 \mathrm{p}$.

Machado, A. A. Ambiental internacional: A construção social do acidente químico ampliado de Bhopal e da convenção174 da OIT. Rio de Janeiro, 28, 7-51, 2006.

Macieira, T. M. R. \& Cerqueira, T. S. D. (2014). Os reflexos dos tratados internacionais na proteção ambiental brasileira (2014). Eco-92 e desenvolvimento sustentável, seus requisitos e a sua (in)eficácia. 2014. Disponível em: <http://www.webartigos.com/artigos/osreflexos-dos-tratados-internacionais-naprotecao-ambiental-brasileira-eco-92-edesenvolvimento-sustentavel-seus-requisitose-a-sua-in-eficacia/121586/>Acesso em: 20 set. 2015.

Navarro, R. M. \& Müller, E. T. C. Um estudo sobre a contabilidade ambiental no setor madeireiro de Imbituva Estado do Paraná. 15 Convenção dos Contabilistas do Paraná Edição nº 21. Curitiba, 2010.

Paiva, Paulo Roberto. Contabilidade ambiental. 1. ed. São Paulo: Atlas, 2003, 154 p. 
Portal da transparência. (2015). Disponível em: <http://www.portaltransparencia.gov.br/ convenios/convenioslista.asp?uf=go\&codmun icipio $=9501 \&$ codorgao $=\&$ tipoconsulta $=$ tr pj2\&periodo $=h t t p: / / c i d a d e s . i b g e . g o v . b r / x t r a s /$ perfil.php?lang $=\&$ codmun $=521520 \&$ search $=\|$ infográficos:-informações-completas.

Prefeitura de Novo Brasil (2015). Contrato da coleta seletiva, 2015. Disponível em: <http://novobrasil.go.gov.br/publica/index.ph p?folder $=2015 \% 2$ FCONTRATOS $\% 2$ FPODE R\%20EXECUTIVO\%2F03\%20marco.

Ribeiro, Maísa de Souza. Contabilidade e Meio Ambiente. Dissertação (mestrado). FEA/USP, 1992. Disponível em: < https://uspdigital.usp.br/tycho/CurriculoLattes Mostrar?codpub=A7A1DCE9C3AA>. Acesso em: 20 set. 2015.

Ribeiro, M. S. (2006). Contabilidade ambiental. $1^{a}$ edição. São Paulo: Saraiva, 220 p.
Ribeiro, M. S. (2010) Contabilidade ambiental. 2 ed. São Paulo: Saraiva.

Tinoco, J. E. P \&; Kraemer, M. E. P. (2008). Contabilidade e gestão ambiental. $2^{\mathrm{a}}$ edição. São Paulo: Atlas.

Tinoco, J. E. \& Kraemer, M. E. P. (2011). Contabilidade e gestão ambiental. $3^{\mathrm{a}}$ edição. São Paulo: Atlas, 296 p.

Recebido em Janeiro 27, 2016

Aceito em Março 26, 2016

License information: This is an open-access article distributed under the terms of the Creative Commons Attribution License, which permits unrestricted use, distribution, and reproduction in any medium, provided the original work is properly cited 